\title{
Imagination and memory: Does imagining implausible events lead to false autobiographical memories?
}

\author{
KATHY PEZDEK \\ Claremont Graduate University, Claremont, California \\ IRIS BLANDON-GITLIN \\ California State University, Fullerton, California \\ and \\ PAMELA GABBAY \\ Claremont Graduate University, Claremont, California
}

\begin{abstract}
Previous studies have reported that imagination can induce false autobiographical memories. This finding has been used to suggest that psychotherapists who have clients imagine suspected repressed memories of childhood sexual abuse may, in fact, be inducing false memories for the imagined events. In this study, at Time 1 and then, 2 weeks later, at Time 2, 145 subjects rated each of 20 events on the Life Events Inventory as to whether each had occurred to them in childhood. One week after Time 1, the subjects were told that 2 target events were plausible and 2 were implausible. They were then asked to imagine 1 plausible and 1 implausible target event. Plausibility and imagining interacted to affect occurrence ratings; whereas imagining plausible events increased the change in occurrence ratings, imagining implausible events had no effect on occurrence ratings.
\end{abstract}

Over the past decade, there has been an abundance of research in cognitive psychology on false memories. A PsycINFO search of the empirical publications in cognitive psychology conducted through January 2004, using the subject heading "false memory," produced 198 articles, all published since 1993 (Pezdek \& Lam, 2007). Among these studies, one manipulation reported to increase the probability of planting false events in memory is the process of imagining the event. Mazzoni and Memon (2003), for example, reported that after imagining a target event, $40 \%$ of participants reported having a memory for the event, in comparison with only $23 \%$ of those in the exposure-only condition. Similar findings were reported by Goff and Roediger (1998), Hyman and Pentland (1996), Lampinen, Odegard, and Bullington (2003), and Lindsay, Hagen, Read, Wade, and Garry (2004). The effect of imagination on memory has also been assessed using the imagination inflation procedure

This article is based on work, supported by the National Science Foundation, conducted by K.P. under Grant SES-9910909. Any opinions, findings, and conclusions or recommendations expressed in this article are those of the authors and do not necessarily reflect the views of the National Science Foundation. Part of this research also served as P.G.'s M.A. thesis. We thank Linda A. Henkel for her thoughtful suggestions on an earlier draft of this article, and Kathryn Sperry for her assistance conducting the word count analysis. Correspondence concerning this article should be addressed to K. Pezdek, Department of Psychology, Claremont Graduate University, Claremont, CA 91711-3955 (e-mail: kathy.pezdek@cgu.edu). (cf. Garry, Manning, Loftus, \& Sherman, 1996; Garry \& Polaschek, 2000), in which imagining events on the Life Events Inventory (LEI) increases belief that the events occurred in one's childhood.

Pezdek, Finger, and Hodge (1997) have suggested one interpretation of how false events can become planted in memory. According to this interpretation, if a suggested false event is judged to be true, a false memory for the event can be constructed from details of the generic event script, as well as from details of related episodes of the event. Memory for the false event thus becomes constructed from this related information in memory. Imagining the false event then would encourage individuals to activate relevant generic and specific details already in memory and to use this information to construct the memory for the false event.

However, Pezdek et al. (1997) and Pezdek and Hodge (1999) reported that false memories are significantly less likely to be suggestively planted for events that are relatively implausible. The operational definition of an implausible event in this line of research is one that is perceived as having a low probability of occurrence for individuals in the cohort tested. Pezdek et al. (1997, Experiment 2) had 20 confederates read descriptions of one true event and two false events to a younger sibling or close relative. The more plausible false event described the relative's being lost in a mall while shopping; the less plausible false event described the relative's receiving an enema. One week later, only 3 participants recalled a false 
event, and all three of the recalled events were the more plausible event, being lost in a mall. This finding was replicated in their Experiment 1, in which a suggested description of a Catholic ritual was more likely to be planted in memory for Catholics than for Jews and vice versa.

The interpretation of these results was that if an individual first determines that a suggested event is implausible and not likely to be true, he or she less persistently searches his or her memory for information relevant to the event. Consequently, images constructed for implausible events will contain less information. On the basis of the source-monitoring framework, memories are more likely to be associated with perceived than with imagined events if they contain (1) more information, (2) qualitatively richer sensory-perceptual and semantic information, and (3) more information about one's thoughts or feelings (Henkel \& Franklin, 1998; Johnson, Hashtroudi, \& Lindsay, 1993).

On the basis of this interpretation, it would be predicted that whereas imagining a plausible event would increase an individual's rating of the occurrence of the event in childhood, imagining an implausible event would have relatively less impact on occurrence ratings. In light of the fact that childhood sexual abuse is a relatively implausible event for most children, this hypothesized relationship is important if the cognitive research on false memories is to be generalized accurately to real-world cases involving memory for childhood sexual abuse. Thus, although previous studies have reported that when manipulated separately, (1) event plausibility and (2) the process of imagining an event can affect the planting of false events in memory, it is important to examine the interactive effect of these two variables.

In this experiment, we tested this hypothesis, using the imagination inflation procedure. At Time 1 and then, 2 weeks later, at Time 2, subjects rated each of 20 events on the LEI as to whether each had occurred to them in childhood. One week after Time 1, the subjects were told that 2 target events were plausible and 2 were implausible. They were then asked to imagine 1 plausible and 1 implausible target event. Although Pezdek and Eddy (2001) have reported that regression toward the mean can account for some of the imagination inflation effect, there is no reason to think that this would confound the findings across conditions in this study.

Plausibility was manipulated in this study with the instructions read to the subjects (for similar manipulations of event plausibility, see Mazzoni, Loftus, \& Kirsch, 2001; Scoboria, Mazzoni, Kirsch, \& Relyea, 2004). Although Scoboria et al. (2004) reported that presenting individuals with base rate information effectively manipulated "general plausibility," they suggested that this might be different from "personal plausibility." However, manipulations of the stated probability of occurrence of an event have been shown to affect individuals' perceptions of the subjective probability that the event occurred to them personally. Pezdek, Blandon-Gitlin, Lam, Ellis, and Schooler (in press), for example, reported that telling adults that a home-administered enema in childhood was a common experience among individuals in their cohort increased their ratings that they had personally experienced an enema in childhood.

In the present study, the plausibility instructions indicated that in the subjects' cohort, each target event had a low probability of occurrence (i.e., only $9 \%$ or $11 \%$ of 1,000 college students in a previous study reported having experienced the event in childhood) or a high probability of occurrence $(89 \%$ or $91 \%)$. It is important to note, in this study, that target events were not selected that were inherently plausible or implausible; rather, plausibility was experimentally manipulated. This design featureunconfouding plausibility with the events themselves - is a strength of this study, because it helps to rule out many alternative explanations for the effect of plausibility reported in previous research.

\section{METHOD}

\section{Subjects and Design}

Students volunteered to participate in five psychology classes at California State University, San Bernardino. They participated after class in groups of about 15 students each and were well spaced throughout the classroom. There were 145 subjects who completed the experiment and were not excluded on the basis of the exclusion criteria specified in the Results section ( $M$ age $=22.55$ years; 45 males and 100 females). This was a 2 (imagined or not imagined) $\times$ 2 (low or high plausibility) within-subjects design.

\section{Materials and Procedure}

The subjects participated in three phases of the experiment. In the first phase, the subjects completed the 20-item LEI similar to that used by Pezdek and Eddy (2001). Self-paced, the subjects first rated each of the 20 events on a scale from 1 (definitely did not happen to me prior to age 10) to 8 (definitely did happen to me prior to age $10)$. In the first phase, a subset of the subjects $(n=68)$ also rated each event on the LEI in terms of whether they had no memory (1), a vague memory (2), or a detailed memory (3) that the event had happened to them prior to age 10 .

Four of the LEI events were target events: "was almost hit by a car," "had been rescued from the water while swimming," "broke a window with your hand," and "found a $\$ 10.00$ bill in a parking lot." The assignment of the four target items to the four within-subjects conditions and the order of presenting the conditions were counterbalanced across subjects. Thus, plausibility and the imagination factor were not confounded with target event in this study; each of the four target events equally often served in the high- and lowplausibility conditions and in the imagination and no-imagination conditions. It was the instructions given in the intervention phase that manipulated plausibility and the imagination factor.

One week later, the subjects returned for the intervention phase. Each subject was given a packet to complete self-paced. The packet conveyed information about each of the four target events on a separate page; two were presented as highly plausible childhood events, and two as low in plausibility. They were then guided to imagine one high- and one low-plausibility event. The other two target events were in the no-imagination condition.

In conveying plausibility information, the subjects were told that we had surveyed 1,000 college students regarding how frequently they had experienced specific events before the age of 10. Each of the four target events in this study was then described as having received a low probability of occurrence (i.e., only $9 \%$ or $11 \%$ of the students in a previous study) or a high probability of occurrence $(89 \%$ or $91 \%)$. After receiving the plausibility information for all four target events, the subjects were asked to recall the probability 
presented for each target event. Those who did not get all four correct were excluded from the study.

Next in the packet, two target events were imagined (one high- and one low-plausibility event). For each of these events, the subjects were given imagining instructions similar to those used by Mazzoni and Memon (2003) and Pezdek and Eddy (2001). The subjects were then instructed to write a detailed description of their image of this event.

One week after the intervention phase, the subjects completed the Time 2 test phase. They filled out the LEI a second time, again providing occurrence ratings following the same procedure as that at Time 1 . The subset of subjects $(n=68)$ again provided memory ratings for each of the 20 events.

\section{RESULTS}

In analyzing the data, there were four exclusion criteria. First, 4 subjects were excluded from the analyses because they responded 8 (definitely did happen) to the LEI events "won a million dollars" or "played for the LA Lakers." Second, six univariate outliers were excluded; these were subjects for whom transformed LEI change scores were $z>3.26$. Third, the Mahalanobis distance procedure suggested by Tabachnick and Fidell (2001, pp. 92-95) was used to identify and exclude two multivariate outliers. Multivariate outliers were defined as any case with a Mahalanobis distance greater than $\chi^{2}(4)=18.47, p<$ .001 . Finally, 14 subjects failed the four-item test of their memory for the plausibility/probability of each of the four target events. The 145 subjects included in the subsequent analyses satisfied these inclusion criteria.

We first determined that the mean occurrence ratings (range $=1-8$ ) at Time 1 were not significantly different among the four conditions [overall $M=2.75 ; F(3)=$ $0.18]$. The data were then scored in terms of the mean change in occurrence ratings from Time 1 to Time 2 for target items in each of the four conditions, defined by manipulations of plausibility and imagination. These datareported as change scores, not absolute ratings - are presented in Figure 1. Given that the baseline absolute ratings averaged 2.75 and did not significantly differ across the four conditions, this leaves ample room in all the condi- tions for an increase or a decrease in ratings following the plausibility and imagination manipulations. Floor effects are thus not of concern.

A $2 \times 2$ within-subjects ANOVA performed on these data revealed a significant main effect of imagination $\left[F(1,144)=4.24, M S_{\mathrm{e}}=2.47, p<.05 ; \eta^{2}=.17\right]$ and $\mathrm{a}$ significant main effect of plausibility $[F(1,144)=10.51$, $\left.M S_{\mathrm{e}}=2.77, p<.01 ; \eta^{2}=.26\right]$. More important, as was predicted, the interaction of imagination and plausibility was also significant $\left[F(1,144)=4.61, M S_{\mathrm{e}}=2.51, p<\right.$ $\left..05 ; \eta^{2}=.18\right]$. Whereas with high-plausibility events, the change in occurrence ratings significantly differed between the imagination and the no-imagination conditions $[t(144)=2.61, p<.01 ; r=.17]$, with low-plausibility events, the change in occurrence ratings was not significantly different between the imagination and the noimagination conditions $[t(144)=0.09 ; r=.01]$. Thus, although imagining a relatively more plausible event increased occurrence ratings that the event had occurred in childhood, imagining a relatively less plausible event did not affect occurrence ratings.

The next analysis assessed how frequently the changes in occurrence ratings for target events from Time 1 to Time 2 increased, decreased, or stayed the same. These data are presented in Figure 2. As can be seen in Figure 2, for the large majority of the events $(61 \%$ across all four conditions), occurrence ratings for the four target events did not change from Time 1 to Time 2, even though 2 weeks transpired between these two points in time. However, when changes did occur, they were more likely to reflect increases ( $28 \%$ across all four conditions) than decreases $(12 \%)$ in occurrence ratings. In particular, as can be seen in the four bars on the right side of Figure 2, whereas occurrence ratings for high-plausibility events were more likely to increase if the event was imagined (38\%) than if it was not (28\%), with low-plausibility events, occurrence ratings were not more likely to increase if imagined (21\%) than if not $(23 \%)$.

We predicted that if individuals considered an event to be relatively plausible, they would more persistently

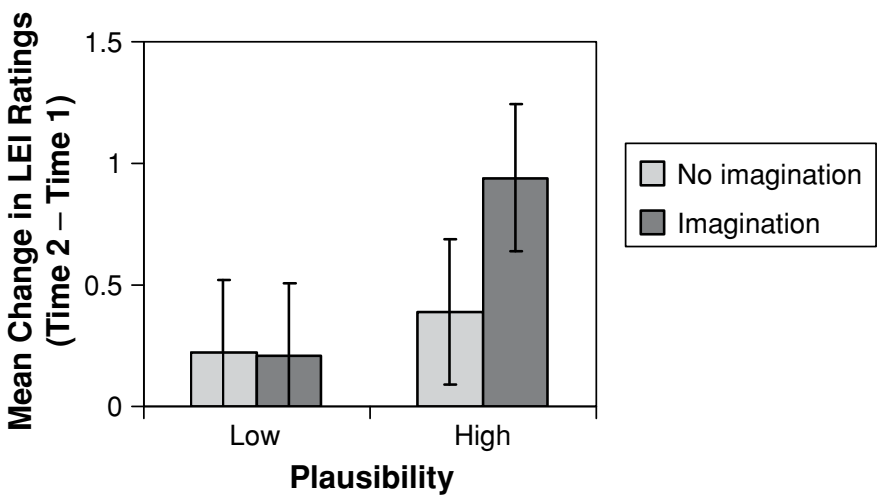

Figure 1. Mean change in occurrence ratings (these difference scores were computed as Time 2 rating - Time 1 rating) to Life Events Inventory (LEI) target events as a function of low- versus high-plausibility manipulations and the presence of imagination instructions or not. 


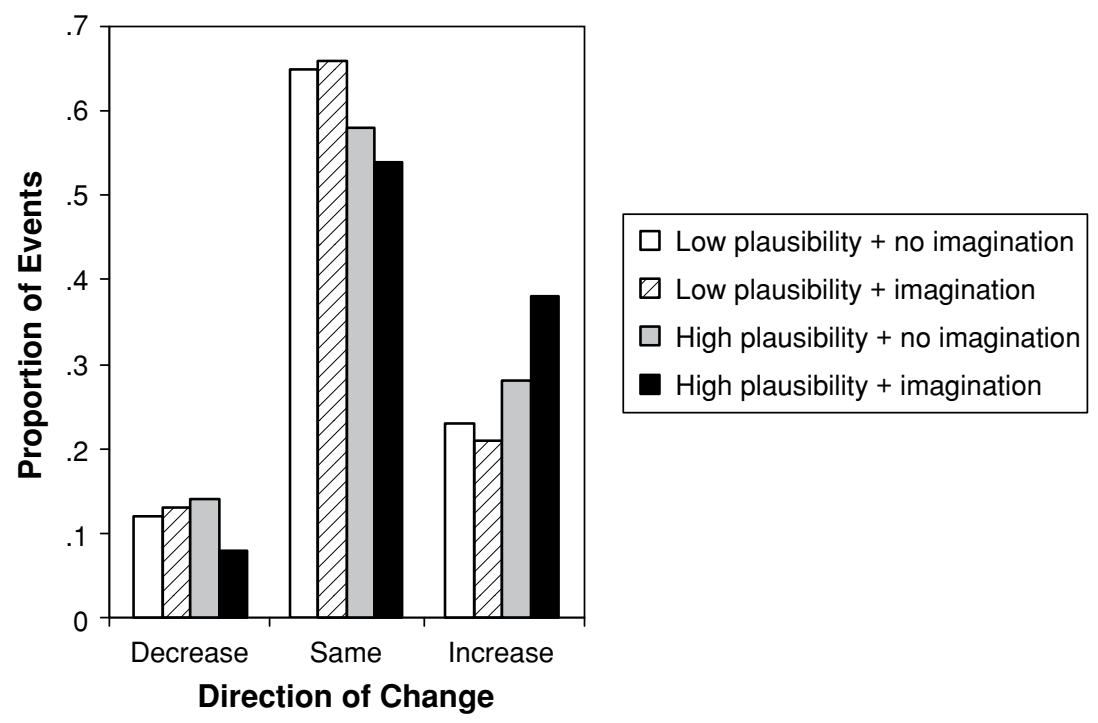

Figure 2. Proportion of the target events in each of the four conditions that decreased, stayed the same, or increased from Time 1 to Time 2.

search their autobiographical memory for information relevant to the event. Accordingly, images constructed for plausible events would contain more information. An additional analysis was conducted to assess this prediction. In this study, the subjects provided a written description of their images for both of the imagined events - one plausible and one implausible. A word count of these descriptions was conducted by a graduate student, blind to the conditions in this study. In conducting this word count, all words were counted except for conjunctions, articles, prepositions, and repetitions of phrases. Protocols of 5 subjects were excluded because they only described why they could not imagine the target event. As was predicted, the word count was significantly higher in the plausible condition $(M=53.87, S D=28.15)$ than in the implausible condition $(M=48.06, S D=29.07)[t(139)=2.99$, $p<.01 ; r=.27]$. This finding is especially compelling in that the assignment of target items to the plausible versus the implausible condition was counterbalanced across subjects.

An alternative account of the change in LEI ratings from Time 1 to Time 2 is that the individuals were basing their occurrence ratings at Time 2 on the plausibility information that was provided (i.e., "I don't remember this event, but they told me that this happens $91 \%$ of the time to respondents so it probably happened to me"). This hypothesis would predict that the change in LEI ratings from Time 1 to Time 2 would be significantly greater for highthan for low-plausibility events in the no-imagination condition, as well as in the imagination condition. As can be seen in Figure 1, in the imagination condition, the change in LEI ratings was significantly greater for high- $(M=$ $.94)$ than for low- $(M=.21)$ plausibility events $[t(144)=$ $3.72, p<.01 ; r=.30]$; however, this difference was not significant in the no-imagination condition [high, $M=$ .39 ; low, $M=.22 ; t(144)=0.89 ; r=.07]$. We acknowl- edge that this lack of significance in the no-imagination condition may reflect a lack of statistical power; however, this is unlikely with a $t$ value $<1.00$.

To assess the relationship between autobiographical beliefs (as assessed by LEI scores) and autobiographical memory, a subset of our subjects $(n=68)$ was asked to rate how vivid their memory was for each target event, on a 1-3 scale. The overall correlation between the change in occurrence ratings and the change in memory vividness ratings for the four target events was significant $(r=.32$, $p<.09)$. A similar significant correlation was reported by Scoboria et al. (2004; $r=.55)$. Together, these results suggest that a significant component of what is assessed with LEI change scores is the self-reported vividness of memory.

\section{DISCUSSION}

The results of this study confirm previous findings that (1) people's occurrence ratings for target events increase as a consequence of imagining the events and (2) in general, plausible events receive higher occurrence ratings than do implausible events. We also presented evidence that the dependent variable, change in occurrence ratings (LEI scores), which assesses changes in individuals' beliefs about what likely occurred in their childhood, is significantly correlated with the clarity of their memories. However, the most important finding is that although imagining events purported to be highly plausible resulted in a significant increase in LEI scores from Time 1 to Time 2, imagining events purported to be of low plausibility did not affect LEI change scores.

One interpretation of the significant interaction of plausibility and imagination is that if people consider an event to be plausible, they will more persistently search their autobiographical memory for relevant details of the event. 
As a consequence, images constructed for plausible events will contain more details and more specificity of detail. At Time 2, then, when the likelihood of each event is rated again, subjects need to make a source-monitoring judgment for each target item to determine whether each was imagined or whether it was actually experienced. Source monitoring typically relies on assessments of the qualitative characteristics of memories, along with judgment processes used to assess them. Memories are more likely to be associated with perceived than with imagined events if they contain more information, qualitatively richer sensory-perceptual and semantic information, and more information about one's thoughts or feelings (Henkel \& Franklin, 1998; Johnson et al., 1993). In addition, sourcemonitoring errors induced by conceptual and physical similarity increase across repeated memory tests (Henkel, 2004). Accordingly, in making source-monitoring judgments at Time 2 in this study, imagined plausible events were more likely to be considered actually experienced than were imagined implausible events. This interpretation is supported by the finding that during the imagining phase in this study, the word count was significantly higher for imagined plausible than for implausible events, even though the assignment of target event to plausibility condition was counterbalanced across subjects.

On the other hand, if people consider a target event to be implausible, during the imagination phase they less persistently search their autobiographical memory to find relevant information. At Time 2, then, their LEI ratings are likely to be similar to those provided at Time 1, because no change in their beliefs about or memory for the event have occurred. It is important to note that these findings did not result because people had less knowledge of or less familiarity with the implausible than with the plausible target events, because in this study, all four target events served equally often in the plausible and the implausible conditions; that is, plausibility was unconfounded with the events themselves.

The cognitive research on false memories has frequently been generalized to cases involving the planting of false memories for childhood sexual abuse (Loftus, 1993), and childhood sexual abuse is a relatively implausible event for most children. The results of this study suggest that although imagining an event can increase people's belief that the event occurred to them, this effect is more likely to occur with relatively plausible than with implausible events. Two qualifications are important. First, although individuals' perceptions of the plausibility that they were sexually abused in childhood are likely to be based on their life experiences, perceptions of the plausibility that one was sexually abused in childhood may also be affected by information conveyed by, for example, a therapist or a parent. In fact, Mazzoni et al. (2001) reported that informing subjects that a highly implausible event - demonic possession - was relatively plausible increased their ratings of the likelihood that they had experienced this event. Second, the types of situations that might arise in psychotherapy are likely to be significantly more intensive than the imagine manipulation in this laboratory experiment and, thus, more likely to impact a change in memory.

Although imagining implausible autobiographical events did not significantly affect LEI change scores in this study, these results should not be taken to imply that it is impossible to imagine bizarre events. In fact, Thomas and Loftus (2002) reported that imagining specific bizarre laboratory tasks led subjects to erroneously remember having performed these tasks. However, there are two important differences between this previous study and the present study. First, in the previous study, the "bizarre" tasks were all trivial and doable (e.g., wrap an eraser in a napkin), and some were actually performed in the experiment. This was not true for the autobiographical target events used in the present study. Second, the previous study used an episodic list-learning task. This is an important difference because a key factor in the bizarre imagery effect is the disruption and enhancement of the encoding of serial order information caused by the bizarre items in the list (cf. DeLosh \& McDaniel, 1996). Serial order information is likely to play a more critical role in an episodic list-learning task than in a test of autobiographical memory.

As a caveat, although significant patterns of results occurred in this study, these results are typical of those in other studies in which LEI scores have been used, in that surprisingly little change in LEI ratings actually occurred. The majority $(61 \%)$ of the LEI ratings were exactly the same at Time 1 and, 2 weeks later, at Time 2 . And although $28 \%$ of the LEI ratings did increase from Time 1 to Time 2, the mean magnitude of the change in LEI ratings for these individuals was only 0.30 on a scale from 1 to 8 . Although significantly higher rates of false memories have resulted with other procedures (cf. Lindsay et al., 2004), the results from this and other, similar studies in which LEI ratings have been used suggest that beliefs about the occurrence of childhood events are actually fairly stable.

\section{REFERENCES}

DeLosh, E. L., \& McDaniel, M. A. (1996). The role of order information in free recall: Application of the word-frequency effect. Journal of Experimental Psychology: Learning, Memory, \& Cognition, 22, 1136-1146.

Garry, M., Manning, C. G., Loftus, E. F., \& Sherman, S. J. (1996). Imagination inflation: Imagining a childhood event inflates confidence that it occurred. Psychonomic Bulletin \& Review, 3, 208-214.

Garry, M., \& PolascheK, D. L. L. (2000). Imagination and memory. Current Directions in Psychological Science, 9, 6-10.

GoFf, L. M., \& RoEdiger, H. L., III (1998). Imagination inflation for action events: Repeated imaginings lead to illusory recollections. Memory \& Cognition, 26, 20-33.

HenKel, L. A. (2004). Erroneous memories arise from repeated attempts to remember. Journal of Memory \& Language, 50, 26-46.

Henkel, L. A., \& Franklin, N. (1998). Reality monitoring of physically similar and conceptually related objects. Memory \& Cognition, 26, 659-673.

Hyman, I. E., JR., \& Pentland, J. (1996). The role of mental imagery in the creation of false childhood memories. Journal of Memory \& Language, 35, 101-117.

Johnson, M. K., Hashtroudi, S., \& Lindsay, D. S. (1993). Source monitoring. Psychological Bulletin, 114, 3-28. 
Lampinen, J. M., Odegard, T. N., \& Bullington, J. L. (2003). Qualities of memories for performed and imagined actions. Applied Cognitive Psychology, 17, 881-893.

Lindsay, D. S., Hagen, L., Read, J. D., Wade, K. A., \& Garry, M. (2004). True photographs and false memories. Psychological Science, 15, 149-154.

LofTus, E. F. (1993). The reality of repressed memories. American Psychologist, 48, 518-537.

Mazzoni, G. A. L., Loftus, E. F., \& Kirsch, E. (2001). Changing beliefs about implausibility autobiographical events: A little plausibility goes a long way. Journal of Experimental Psychology: Applied, 7, 51-59.

Mazzoni, G. [A. L.], \& Memon, A. (2003). Imagination can create false autobiographical memories. Psychological Science, 14, 186-188.

Pezdek, K., Blandon-Gitlin, I., Lam, S., Ellis, R. E., \& SchoolER, J. W. (in press). Is knowing believing? The role of event plausibility and background knowledge in planting false beliefs about the personal past. Memory \& Cognition.

PezdeK, K., \& EdDy, R. M. (2001). Imagination inflation: A statistical artifact of regression toward the mean. Memory \& Cognition, 29, 707-718.
Pezdek, K., Finger, K., \& Hodge, D. (1997). Planting false childhood memories: The role of event plausibility. Psychological Science, $\mathbf{8}$, 437-441.

Pezdek, K., \& Hodge, D. (1999). Planting false childhood memories in children: The role of event plausibility. Child Development, $\mathbf{7 0}$, 887-895.

PeZDEK, K., \& LAM, S. (2007). What research paradigms have cognitive psychologists used to study "false memory," and what are the implications of these choices? Consciousness \& Cognition, 16, 2-17.

Scoboria, A., Mazzoni, G., Kirsch, I., \& Relyea, M. (2004). Plausibility and belief in autobiographical memory. Applied Cognitive Psychology, 18, 791-807.

Tabachnick, B. G., \& Fidell, L. S. (2001). Using multivariate statistics (4th ed.). Boston: Allyn \& Bacon.

Thomas, A. K., \& Loftus, E. F. (2002). Creating bizarre false memories through imagination. Memory \& Cognition, 30, 423-431.

(Manuscript received November 9, 2005; revision accepted for publication January 30, 2006.) 